\title{
LC-MS/MS METHOD FOR L-DOPA QUANTIFICATION IN DIFFERENT TISSUES OF VICIA FABA
}

\author{
JESSY PAVÓN-PÉREZ ${ }^{a}$, CLAUDIA A. OVIEDO ${ }^{b}$, MHARTYN ELSO-FREUDENBERG $^{b}$, \\ KAREM HENRÍQUEZ-AEDO ${ }^{a, c}$ AND MARIO ARANDA ${ }^{{ }^{*}}$ \\ ${ }^{a}$ Laboratorio de Biotecnología y Genética de los Alimentos, Departamento de Ciencia y Tecnología de los Alimentos, Facultad de Farmacia, Universidad de \\ Concepción. \\ ${ }^{b}$ Departamento de Química, Facultad de Ciencias, Universidad del Bio Bio. \\ Centro de Biotecnología, Universidad de Concepción. \\ ${ }^{d}$ Laboratorio de Investigación en Fármacos y Alimentos, Departamento de Farmacia, Facultad de Química y de Farmacia, Pontificia Universidad Católica de \\ Chile.
}

\begin{abstract}
A rapid, sensitive, precise and accurate liquid chromatography tandem mass spectrometry (LC-MS/MS) method was developed for levo 3,4-dihydroxyphenylalanine (L-DOPA) determination in Vicia faba during different growth stages. The method applied a simple sample preparation step followed by a chromatographic separation on a Kinetex XB Core-Shell $\mathrm{C}_{18}(100 \mathrm{~mm}$ x $4.6 \mathrm{~mm}, 2.6 \mu \mathrm{m})$ column, using a mixture of ultrapure pure water (A) with $0.5 \%(\mathrm{v} / \mathrm{v})$ formic acid and methanol (B) as mobile phase. Analysis of L-DOPA was carried out by MS/MS applying a Multiple Reaction Monitoring (MRM) method using the transition $m / z 198 \rightarrow m / z, 152$. This LC-MS/MS method allowed a well-resolved detection of L-DOPA in $c a .2$ min within 6 min run. Method was validated showing a linear range from 0.05 to 10 $\mathrm{mg} \mathrm{L}^{-1}\left(R^{2}=0.99\right)$; repeatability showed RSD value of $1.40 \%$. Recoveries ranged from 94.14 to $116.62 \%$ with RSD values $\leq 5.66 \%$ and detection and quantification limits were 0.01 and $0.05 \mathrm{mg} \mathrm{L}^{-1}$, respectively. Applying this validated method, L-DOPA was determined in Vicia faba samples to determined its tissue distribution. As expected, a broad range of L-DOPA content finding the lowest content in seeds $\left(4.72 \pm 2.12 \mathrm{mg} \mathrm{g}^{-1}\right)$ and the highest in sprouts $\left(133.60 \pm 5.65 \mathrm{mg} \mathrm{g}^{-1}\right)$.
\end{abstract}

Keywords: Mass spectrometry, L-DOPA, Vicia faba, LC-MS/MS

\section{INTRODUCTION}

The imbalance of dopamine and acetylcholine in the brain may cause a progressive neurodegenerative condition like Parkinson's disease (PD) ${ }^{1}$. Currently, the use of levo 3,4-dihydroxyphenylalanine (L-DOPA) as a precursor of dopamine is the standard therapy for PD treatment ${ }^{2}$. Nevertheless, synthetic L-DOPA can cause a several side effects including nausea, vomiting, low blood pressure, drowsiness, and restlessness ${ }^{2}$. L-DOPA is a nonprotein amino acid synthesized from L-tyrosine ${ }^{3}$, that can be found in animals and in some plants ${ }^{4}$. It has an important roles in plants like defense against insects and it can affect the growth and development of neighboring plants ${ }^{5}$. The L-DOPA content in legumes is relatively high, particularly in the Fabaceae family ${ }^{6}$. It has been demonstrated that Vicia fava consumption can improve patient's motor functions ${ }^{7}$. This effect might be enhanced by the concomitant presence in fava beans of carbidopa, a peripheral inhibitor of the enzyme DOPA decarboxylase ${ }^{8}$. Several methods have been applied to determined L-DOPA in different kind of legumes. Raina et $\mathrm{al}^{9}$ applied a high-performance thin-layer chromatography (HPTLC) to determine L-DOPA content in Mucuna Pruriens germplasm finding concentrations between 2.23 and 5.36\%. Burbano et al ${ }^{10}$ used high performance liquid chromatography (HPLC) determining a L-DOPA content from 60 to 67.5 $\mathrm{mg} \mathrm{g}^{-1}$ (dry weight) in young pods of $V$. faba cultivars. Etemadi et $\mathrm{al}^{2}$ studied LDOPA distribution in plant tissues of faba bean, the highest concentration $\left(13.3 \mathrm{mg} \mathrm{g}^{-1}\right)$ was found in young seedlings and its content decreased proportionally with plant maturity. When plants were harvested at physiological maturity, the highest L-DOPA content was detected in leaves $\left(10.5 \mathrm{mg} \mathrm{g}^{-1}\right)$ followed by flowers, young pods, mature seeds, and roots. Recently, Oviedo et al ${ }^{11}$ found concentrations as high as $125 \mathrm{mg} \mathrm{g}^{-1}$ in sprouts of fava bean using a HPTLC-UV method.

The main drawback of HPLC and HPTLC coupled to spectrophotometric detection is the lack of an unequivocal identification, which could lead to inaccurate quantification. HPLC coupled with mass spectrometry allows a significant improvement in quantitative analytical methods, in terms of sensitivity and specificity. Thus, the objective of this work was to develop a novel LC-MS/MS method for an accurate and selective evaluation of L-DOPA in faba bean. After validation, method was applied to evaluate the effect of tyrosine on L-DOPA content during plant growth.

\section{MATERIALS AND METHODS}

\subsection{Reagents, standards and samples}

Potassium phosphate (>99\%), ethanol absolute, dichloromethane $(99.9 \%)$, isopropanol (99.8\%), acid acetic (96\%), LC-grade methanol and formic acid (98$100 \%$ ) were obtained from Merck (Darmstadt, Germany). Polyvinylpyrrolidone (PVP) was purchased from Calbiochem (Selangor, Malaysia). Buffered solutions and mobile phase were prepared with ultrapure water $(18.2 \mathrm{M} \Omega \mathrm{cm})$ produced by means of Simplicity system from Millipore (Bedford, MA, USA). L-DOPA standard was purchased from Sigma (St. Louis, MO, USA). L-DOPA stock solution of $100 \mathrm{mg} \mathrm{L}^{-1}$ was prepared in ultrapure pure water with $0.1 \%(\mathrm{v} / \mathrm{v})$ formic acid. Standard solutions were obtained by aliquot dilution from stock solution.

\subsection{Plant extracts}

Control and tyrosine irrigated $V$. faba plants were grown ${ }^{11}$ and then roots, sprouts and seeds were sampled along plant development. L-DOPA content was determined in each type of sample at the following seedling developmental stage: 3-4 days (A); 8-9 days (B) or 2-4 leaves (C, 15 days approx.). One gram of each tissue was manually ground with a mortar in $3-6 \mathrm{~mL}$ of cold extraction buffer ( $0.05 \mathrm{M}$ potassium phosphate buffer $\mathrm{pH} 6.5,0.5 \%$ (w/v) polyvinylpyrrolidone).

\subsection{L-Dopa content in $V . f a b a$}

Briefly, freeze dried samples $\left(-55^{\circ} \mathrm{C}\right.$ for $\left.48 \mathrm{~h}\right)$ of each organ were ground for $30 s$ at $5000 \mathrm{rpm}$ using a Bertin Instruments (Montigny-le-Bretonneux, Francia), Precellys 24 homogenizer. 50-200 mg of each sample was extracted at room temperature during $2 \mathrm{~h}$ at $120 \mathrm{rpm}$ with $2 \mathrm{~mL}$ of formic acid: ethanol $(1: 1 \mathrm{v} / \mathrm{v})$. Thereafter, samples were centrifuged for $10 \mathrm{~min}$ at $10,000 \times \mathrm{g}$ and supernatants were collected. This extraction process was repeated 4 times and a fifth and final extraction was carried out using the same conditions but overnight. All supernatants were pooled and centrifuged for $10 \mathrm{~min}$ at $10,000 \times \mathrm{g}$. These collected supernatants were used as the respective fava bean extracts injected on the HPLC system for further analysis. Before LC analysis all samples were filtered through a $13 \mathrm{~mm}$ PVDF syringe filter $(0.22 \mu \mathrm{m})$. 


\subsection{Liquid chromatography - tandem mass spectrometry}

LC-MS/MS analyses were performed in Shimadzu (Kyoto, Japan) Nexera X2 UHPLC system consisted of: LC-30AD pump, DGU-20A5R degassing unit, SIL-30AC autosampler, CTO-20AC column oven, CBM-20A communication module, SPD-M20A diode array detector (DAD) and LCMS-8030 triple quadrupole (TQ) mass spectrometer. The system was controlled by Shimadzu LabSolution 5.8 software. Separation was carried out on Phenomenex (Torrance, CA, USA) Kinetex XB Core-Shell $\mathrm{C}_{18}$ column $(100 \mathrm{~mm}$ x $4.6 \mathrm{~mm}, 2.6 \mu \mathrm{m})$, thermostated at $35^{\circ} \mathrm{C}$, using a mobile phase composed of $50 \%$ ultrapure water with $0.5 \%$ (v/v) formic acid and $50 \%$ methanol, at a flow rate of $0.5 \mathrm{~mL} \mathrm{~min}^{-1}$. MS/MS analysis was performed using the following conditions: ESI+ voltage $4.5 \mathrm{kV}$; collision energy $-20.0 \mathrm{~V}$; nebulizer gas $\left(\mathrm{N}_{2}\right) 3 \mathrm{~L} \mathrm{~min}^{-1}$, desolvation gas $\left(\mathrm{N}_{2}\right) 18 \mathrm{~L} \mathrm{~min}^{-1}$; desolvation line temperature $250^{\circ} \mathrm{C}$ and heat block temperature $400^{\circ} \mathrm{C}$. Full scan spectra were acquired from $\mathrm{m} / \mathrm{z} 50$ to 1200 . Quantification was performed in Multiple Reaction Monitoring (MRM) detecting the transition $m / z, 198 \rightarrow m / z 152$

\subsection{Statistical analysis}

Data were evaluated using descriptive statistics [mean, standard deviation (SD) and relative standard deviation (RSD)]. L-DOPA calibrations were established applying a linear regression model. Calibrations with and without matrix were compared using F-test. Differences on L-DOPA content were evaluated through Tukey test. All above tests were done with a significance level $(\alpha)$ of 0.05 using GraphPad (San Diego, CA, USA) Prism 6.0 software.

\section{RESULTS AND DISCUSSION}

Selection of adequate transitions is one of the key step to develop quantitative MS-based method. In this work parent and fragment markers were established using pure standard and then spiked samples. L-DOPA mass spectrum showed a protonated molecule $(\mathrm{M}+\mathrm{H})^{+}$at $\mathrm{m} / \mathrm{z} 198$, which is coincident with the reported elsewhere ${ }^{12}{ }^{13}$. After parent ion selection, product ion analysis was carried out to define the most suitable transition for MS/MS detection. From all ions observed in product ions scan mode, $\mathrm{m} / \mathrm{z} 152$ was chosen because showed the most intense and repeatable signal. This ions is the result of losing of $\mathrm{m} / z 46$, which correspond to $\left[(\mathrm{M}+\mathrm{H})-\mathrm{H}_{2} \mathrm{O}-\mathrm{CO}\right]^{+}$fragment (Figure 1). Thus, MS/MS analysis of L-DOPA by MRM was performed using the transition $m / z 198 \rightarrow m / z 152$ that showed adequate intensities at $1 \mathrm{mg} \mathrm{L}^{-1}$, which is in the same concentration range found in samples (Figure 1).

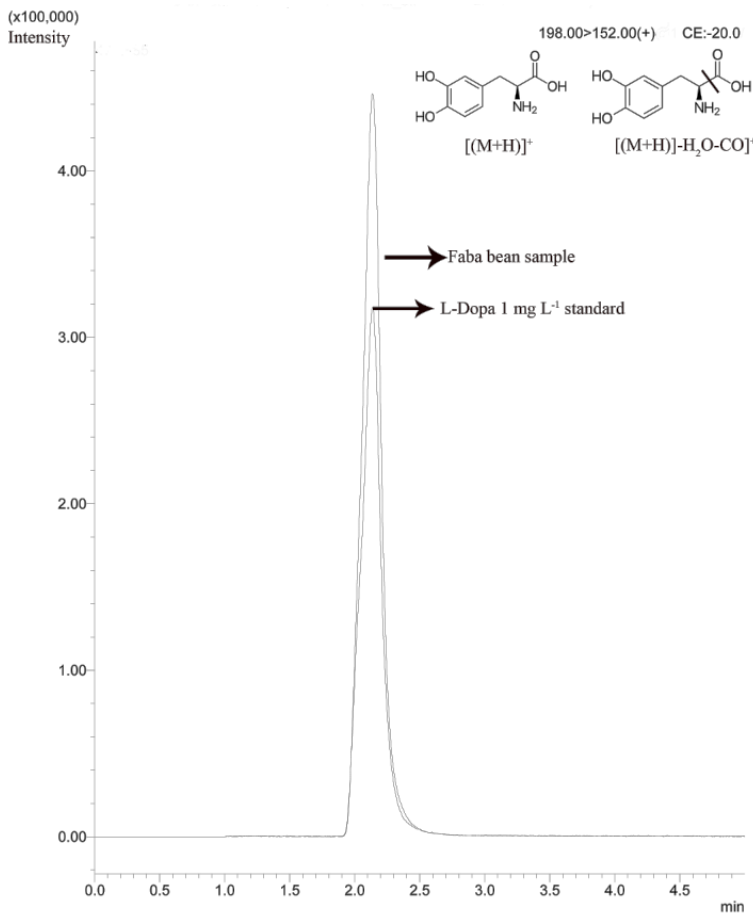

Figure 1. LC-MS/MS chromatograms of standard $1 \mathrm{mg} \mathrm{L}^{-1}$ of L-DOPA and faba bean sprout analyzed in MRM mode.

\subsection{Method validation}

Validation was carried out following the International Conference on Harmonization recommendations ${ }^{14}$. A complete analysis was achieved in 6 min (Figure 1) which is $c a$. $20 \%$ lower than the reported by Etemadi et $\mathrm{al}^{2}$. Calibration curve was established with and without matrix in order to evaluate a possible matrix effect. Since slopes were statistically different $(P<0.05)$ calibrations were established with faba bean matrix using six levels in triplicate from 0.05 to $10 \mathrm{mg} \mathrm{L}^{-1}$. Calibration data fit a linear regression model with determination coefficient $\mathrm{R}^{2}=0.99$. Considering an injection volume of $10 \mu \mathrm{L}$, detection and quantification limits were 0.01 and $0.05 \mathrm{mg} \mathrm{L}^{-1}$, respectively. Detection and quantification limits were much lower than those reported by Singh et al ${ }^{15}$ using HPLC/UV method (LOD $0.69 \mathrm{mg} \mathrm{L}^{-1}$; LOQ $2.09 \mathrm{mg} \mathrm{L}^{-1}$ ). Repeatability was studied injecting in sextuplicate $(n=6)$ a spiked faba bean sample (5.00 mg L $\mathrm{m}^{-1}$ ) showing RSD value of $1.40 \%$. Method accuracy was determined via recovery evaluation. Faba bean samples spiked at three levels $\left(2.5,5.0\right.$ and $\left.7.5 \mathrm{mg} \mathrm{L}^{-1}\right)$ were prepared and analyzed daily during three days. Recovery yields between 94.14 to $116.62 \%$ with RSD values $\leq 5.66 \%$ were obtained. Comparatively, this method showed higher recovery results than the obtained by Li et al $(55 \%)^{13}$.

\subsection{Samples analysis}

Samples analyzed showed a L-DOPA content from 4.72 to $133.60 \mathrm{mg} \mathrm{g}^{-1}$. According to results, higher concentrations were found in plants irrigated with water (control) than with tyrosine (Figure 2). Tyrosine amendment to faba bean plants was considered to verify if it affects L-DOPA content in faba bean, as LDOPA would be produced via the oxidation of tyrosine by the enzyme tyrosinase (tyrosine oxidase) ${ }^{16}$. In plants, tyrosine derives from the shikimic acid pathway and the same enzyme would be involved in L-DOPA synthesis as well ${ }^{17}$. The results obtained are in agree with the ones reported by Oviedo et al ${ }^{11}$ by highperformance thin-layer chromatography HPTLC-UV (Table 1).

\section{Seeds}
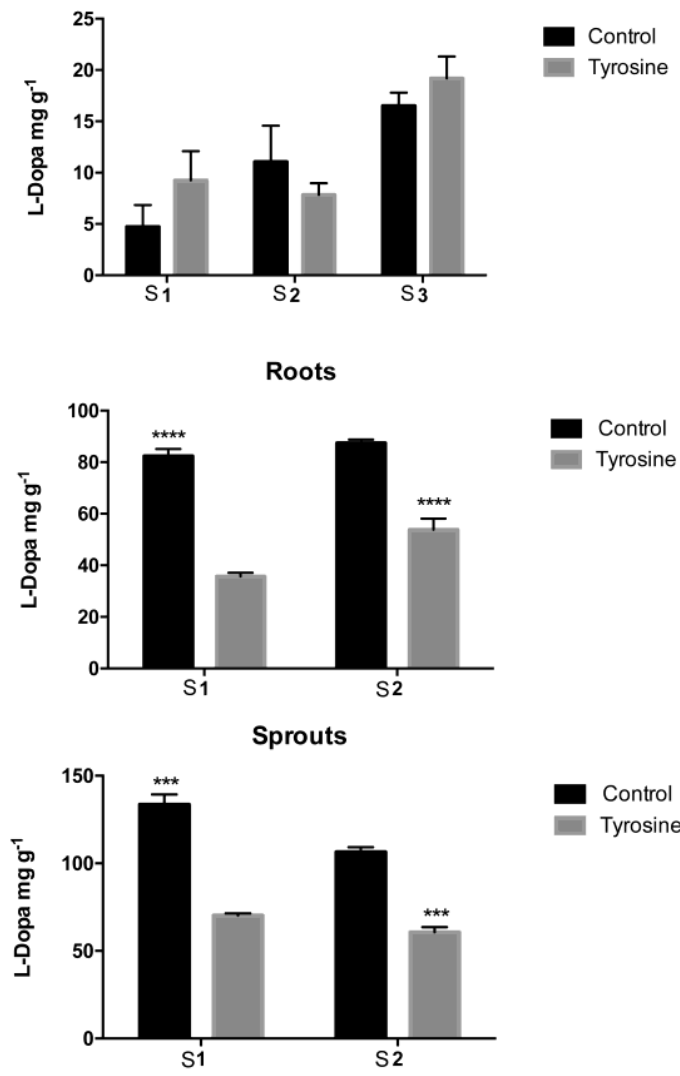

Figure 2. L-Dopa content in control and tyrosine treated samples in different Vicia faba tissues at the early stages of development: S1: 3-4 days, S2:8-9 days, and S3: 15 days approximately. * indicates significant differences between controls and tyrosine treatments according to Tukey test $(P<0.05)$. 
Table 1. L-DOPA content $\left(\mathrm{mg} \mathrm{g}^{-1}\right)$ in different control $V$. faba tissues.

\begin{tabular}{|c|c|c|c|c|c|c|}
\hline \multirow{2}{*}{ Stages } & \multicolumn{3}{|c|}{ HPTLC-UV 11 } & \multicolumn{3}{c|}{ UHPLC-MS/MS (This research) } \\
\cline { 2 - 7 } & Seed & Root & Sprout & Seed & Root & $*$ \\
\hline S1 (3-4 days) & $4.40 \pm 0.06$ & $*$ & $*$ & $4.72 \pm 2.12$ & $*$ & $82.41 \pm 2.72$ \\
\hline S2 (8-9 days ) & $8.07 \pm 1.30$ & $88.50 \pm 5.54$ & $125.87 \pm 17.18$ & $11.05 \pm 3.53$ & $133.60 \pm 5.65$ \\
\hline S3 (15 days approx ) & $14.27 \pm 0.38$ & $89.67 \pm 1.76$ & $113.60 \pm 9.53$ & $16.50 \pm 1.30$ & $87.46 \pm 1.31$ & $106.40 \pm 2.82$ \\
\hline
\end{tabular}

* Nonexistent organ.

$n=3$, three injections for each sample, results are expressed as mean \pm standard deviation.

In the case of plants treated with tyrosine, the lowest concentrations were found in seeds, nevertheless an increase over germination was observed. No significant differences were observed between the different growth stages $(\mathrm{P}>0.05)$. In both, control and treated samples, highest contents were found in roots and sprouts, an increasing trend in time was also observed. Concentrations as high as $133.60 \mathrm{mg} \mathrm{g}^{-1}$ were observed in sprout (S2 stage: 8-9 days) which is 10 times higher than the concentration found in seeds in the same stage $\left(11.05 \mathrm{mg} \mathrm{g}^{-1}\right)$. Indeed the concentration in sprouts and roots was increased over time which is consistent with the results obtained by Goyoaga et $\mathrm{al}^{18}$. The highest concentrations were found in sprouts, which increased over time. Significant statistical differences were observed between the different stages $(\mathrm{P}<0.05)$ except in seeds.

\section{CONCLUSIONS}

This work reports a novel LC-MS/MS method for a reliable quantification of L-DOPA in faba bean. LC-MS/MS method allowed a well-resolved detection of L-DOPA in $c a .2 \mathrm{~min}$ within $6 \mathrm{~min}$ run. Considering validation results the method proved to be reliable, accurate and precise. It was possible to quantify much lower concentrations than those analyzed previously by HPTLC-UV. All faba bean samples analyzed showed the presence of L-DOPA, the highest concentrations were consistently found in $V$. faba sprout tissue.

\section{ACKNOWLEDGMENTS}

Authors want to thank to National Commission of Scientific and Technological Research (CONICYT) of the Chilean Government for the doctoral scholarship granted N ${ }^{\circ}$ 63140062. To Research Assistant Grant of Escuela de Graduados Universidad del Bio-Bio RA N $\mathrm{N}^{\circ} 352 / 649 / 2017$. This work was financially supported by National Fund for Scientific \& Technological Development (FONDECYT), project $\mathrm{N}^{\circ} 1171857$, FONDEQUIP 130209, DIUBB grant $\mathrm{N}^{\circ}$ 165006 3/R and the University of Concepcion.

\section{REFERENCES}

1. S. Patil, O. Apine, S. Surwase, J. Jadhav, APD. 2, 7, (2013).

2. F. Etemadi, M. Hashemi, R. Randhir, O. ZandVakili, A. Ebadi, J. Crop Prod. $6,426,(2018)$.

3. R. Randhir, K. Shetty, Process Biochem. 39, 1775, (2004).

4. C.M. Gautam M, Azmi W, Ann Phytomed. 1, 1, (2012).

5. S. Nidhi, Ann. Plant Sci. 4, 1109, (2015).

6. S. Inamdar, S. Joshi, J. Jadhav, V. Bapat, Nat. prod. bioprospect. 2, 16, (2012).

7. L. Raguthu, S. Varanese, L. Flancbaum, E. Tayler, A. Di Rocco, Eur J Neurol. $16,171,(2009)$.

8. M. Mehran S M, G. B, J Clin Diagn Res : JCDR. 7, 1004, (2013).

9. A.P. Raina, R. Khatri, Indian J. Pharm. Sci. 73, 459, (2011).

10. C. Burbano, C. Cuadrado, M. Muzquiz, J.I. Cubero, Plant Foods Hum Nutr. 47, 265, (1995)

11. C. Oviedo, M. Elso-Freudenberg, M. Aranda, Appl. Sci. 8, 2431, (2018).

12. K. Igarashi, K. Hotta, F. Kasuya, K. Abe, S. Sakoda, J. chromatogr. B. 792, 55, (2003).

13. [13] W. Li, D.T. Rossi, S.T. Fountain, J Pharm Biomed Anal. 24, 325, (2000).

14. International Conference on Harmonisation (ICH), 2005.

15. R. Singh, P. Saini, S. Mathur, G. Singh, S. Kumar, Int. J. Green Pharm. 4, $156,(2010)$.

16. S. Raghavendra, C.K. Ramesh, V. Kumar, M.H. Moinuddin Khan, Front Life Sci 5, 127, (2011).

17. C.A. Schenck, H.A. Maeda, Phytochemistry 149, 82, (2018).

18. C. Goyoaga, C. Burbano, C. Cuadrado, A. Varela, E. Guillamón, M.M Pedrosa, M. Muzquiz, Eur Food Res Technol. 227, 1537, (2008). 